\title{
Erratum to: Mosaic variegated aneuploidy in mouse BubR1 deficient embryos and pregnancy loss in human
}

\author{
Michael Schmid • Claus Steinlein • Qi Tian • Amy E. Hanlon Newell • \\ Manfred Gessler • Susan B. Olson • Andreas Rosenwald • Burkhard Kneitz • \\ Lev M. Fedorov
}

Published online: 30 September 2014

C) Springer Science+Business Media Dordrecht 2014

\section{Erratum to: Chromosome Research DOI 10.1007/s10577-014-9432-x}

In this article Chromosome Res., 22:3, 375-392, 2014, published online: 1 July 2014, enumeration of chromosomes on karyogram shown in Figure $6 \mathrm{~b}$ is not correct. The figure 6 with the correct enumeration (in figure $6 \mathrm{~b}$ ) is presented below.

The correct karyotype is " $39, \mathrm{XYY},-3,-10$ ".

The authors regret this error.

The online version of the original article can be found at http://dx. doi.org/10.1007/s10577-014-9432-x.

M. Schmid • C. Steinlein

Department of Human Genetics, Biocenter, University of Würzburg, 97074 Würzburg, Germany

Q. Tian • L. M. Fedorov $(\bowtie)$

Transgenic Mouse model Shared Resource, Knight Cancer Institute, Oregon Health \& Science University, L481, 3181 SW Sam Jackson Park Road, Portland, OR 97239, USA

e-mail: fedorovl@ohsu.edu

\section{A. E. Hanlon Newell • S. B. Olson}

Cytogenetics Research Laboratory, Department of Molecular and Medical Genetics, Oregon Health \& Science University, Portland, OR 97239, USA

M. Gessler

Developmental Biochemistry, Theodor-Boveri-Institute, Biocenter, University of Würzburg, 97074 Würzburg, Germany

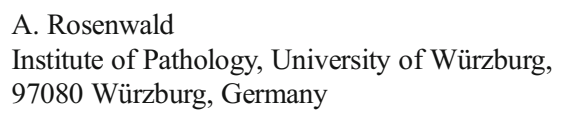

A. Rosenwald

Institute of Pathology, University of Würzburg, 97080 Würzburg, Germany

B. Kneitz $\cdot$ L. M. Fedorov

Physiological Chemistry, University of Würzburg, 97074 Würzburg, Germany

B. Kneitz

Department Urology and Pediatric Urology, University of Würzburg, 97080 Würzburg, Germany 

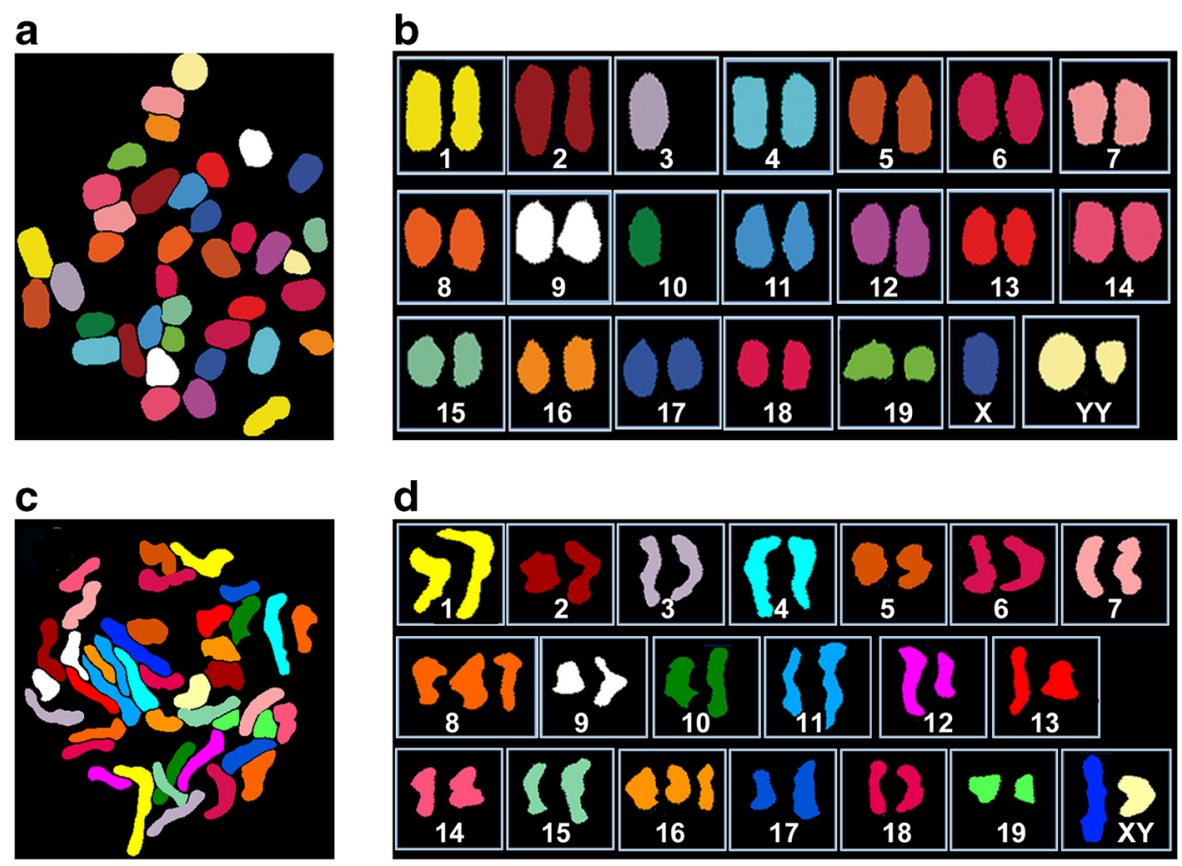

d

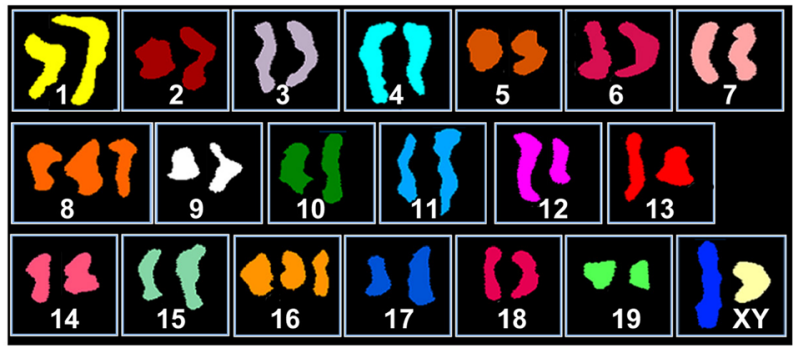

e

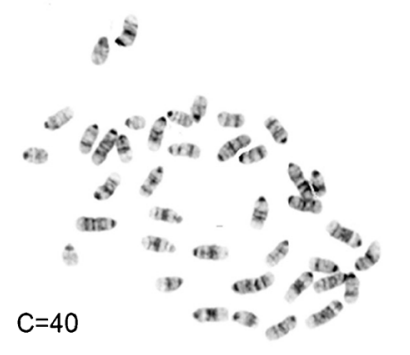

f

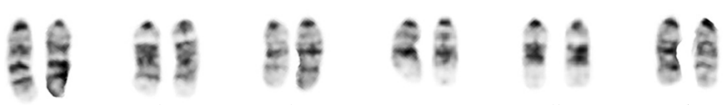

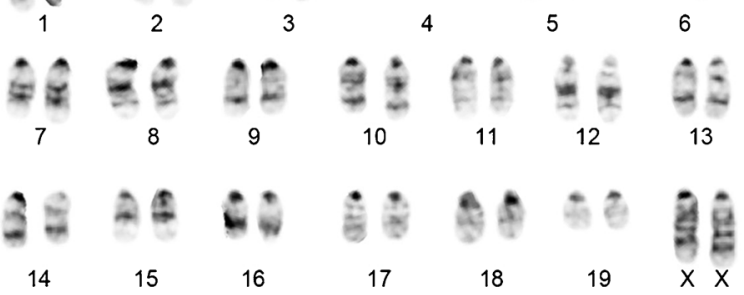

